\title{
Single cell dynamics determine strength of chaos in collective network dynamics
}

\author{
Michael Monteforte ${ }^{1,2^{*}}$, Fred Wolf ${ }^{2}$ \\ From Twentieth Annual Computational Neuroscience Meeting: CNS*2011 \\ Stockholm, Sweden. 23-28 July 2011
}

Cortical neurons have been found to exhibit a much higher action potential (AP) onset rapidness than expected from standard biophysical neuron models [1]. This has raised fundamental physiological questions about the origin of this phenomenon [1,2]. An important issue for the understanding of information processing in the cortex is the impact of rapid AP initiation on the collective dynamics of cortical networks. Here, we report that it in fact strongly reduces the information loss in chaotic cortical networks.

As a model of cortical networks, we analyzed spiking neuron networks in the balanced state [3]. The balanced state provides an explanation of the temporally irregular activity of cortical networks observed in vivo[4]. In this state neurons are driven by large input fluctuations, resulting from a dynamical balance of excitation and inhibition.

Networks of theta neurons in the balanced state exhibit strongly chaotic dynamics [5]. We recently performed an exact analysis of the full spectra of Lyapunov exponents in such networks, revealing that deterministic chaos is extensive and information is lost at strikingly high rates of up to 1 bit per spike per neuron. The theta neuron model, however, shares the relatively low AP onset rapidness of other biophysical standard neuron models.

Here we show that increasing the AP onset rapidness of single neurons strongly reduces the intensity of chaos in balanced networks. Based on the theta neuron model, we developed a new neuron model with variable AP onset rapidness, called the rapid theta neuron model. Parametrically increasing the AP onset rapidness in the neurons reduced the information loss in the chaotic network dynamics and could even induce a transition to stable irregular dynamics (Fig. 1).

These results reveal that the action potential rapidness of single neurons plays an important role in the
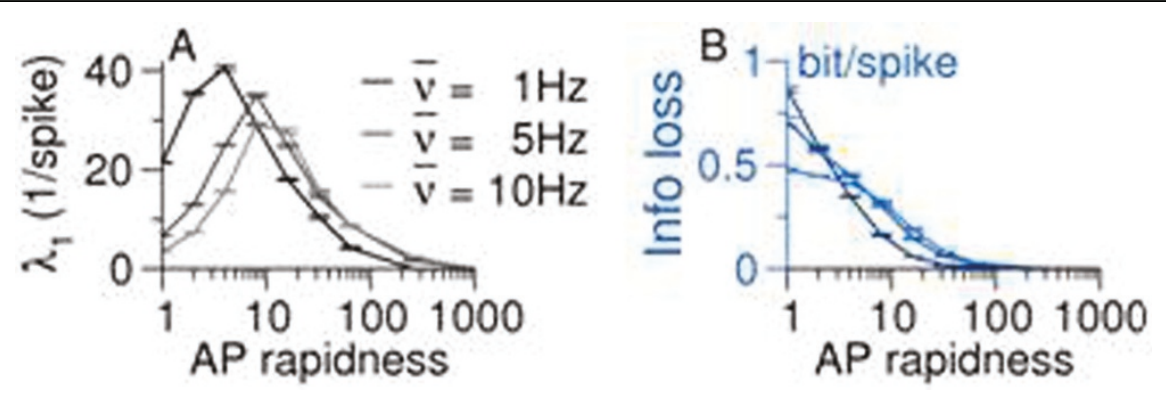

Figure 1 Largest Lyapunov exponent $(\mathbf{A})$ and rate of information loss (B) versus AP onset rapidness in balanced networks of rapid theta neurons at three different average firing rates 1,5 and $10 \mathrm{~Hz}$.

\footnotetext{
* Correspondence: monte@nld.ds.mpg.de

'Max-Planck-Institute for Dynamics and Self-Organization, 37073 Goettingen,

Germany

Full list of author information is available at the end of the article
}

\section{() Biomed Central}

(c) 2011 Monteforte and Wolf; licensee BioMed Central Ltd. This is an open access article distributed under the terms of the Creative Commons Attribution License (http://creativecommons.org/licenses/by/2.0), which permits unrestricted use, distribution, and reproduction in any medium, provided the original work is properly cited. 
collective dynamics of cortical networks. A rapid AP initiation reduces the information loss due to the chaotic dynamics. Our results thus suggest that cortical neurons may have evolved their rapid AP initiation in order to reduce the information loss in chaotic cortical networks and tune the network dynamics towards the edge of chaos.

\section{Author details}

${ }^{1}$ Max-Planck-Institute for Dynamics and Self-Organization, 37073 Goettingen, Germany. ${ }^{2}$ BCCN, BFNT and Georg August University of Goettingen, 37073

Goettingen, Germany.

Published: 18 July 2011

\section{References}

1. Naundorf B, Wolf F, Volgushev M: Unique features of action potential initiation in cortical neurons. Nature 2006, 440:1060-1063.

2. McCormick DA, Shu Y, Yu Y: Hodgkin and Huxley model - still standing? Nature 2006, 445:E1-E2, and the reply Naundorf B, Wolf F, Volgushev M, Nature 2006, 445:E2-E3

3. Van Vreeswijk C, Sompolinsky H: Chaos in Neuronal Networks with Balanced Excitatory and Inhibitory Activity. Science 1996, 274:1724-1726.

4. Softky WR, Koch C: The highly irregular firing of cortical cells is inconsistent with temporal integration of random EPSPs. Journal of Neuroscience 1993, 13(1):334-350.

5. Monteforte $M$, Wolf $F$ : Dynamical entropy production in spiking neuron networks in the balanced state. Physical Review Letters 2010, 105(26):268104-268108.

\section{Submit your next manuscript to BioMed Central} and take full advantage of:

- Convenient online submission

- Thorough peer review

- No space constraints or color figure charges

- Immediate publication on acceptance

- Inclusion in PubMed, CAS, Scopus and Google Scholar

- Research which is freely available for redistribution

Submit your manuscript at www.biomedcentral.com/submit 